\title{
Assessing the sustenance and evolution of social and cultural contexts with sustainable urban development
}

\author{
H. S. Choi ${ }^{1} \&$ K. H. Ahn ${ }^{2}$ \\ ${ }^{I}$ Oxford Brookes University, $U K$ \\ ${ }^{2}$ Seoul National University, Korea
}

\begin{abstract}
A sustainable urban vision needs to reflect the distinctive qualities, characteristics and identities of each individual city. This vision is also an expression of the integrated values and perspectives the inhabitants of each city have for what should be sustained. This paper provides a spatial assessment framework for discussing a new model, with suggestions for sustainable design alternatives in relation to urban design principles and practices, focusing in particular on development within the Multifunctional Administrative City in South Korea.

Keywords: social and cultural sustainability, local identity, contemporary new town development.
\end{abstract}

\section{Introduction}

Sustainability is a key issue in urban transformation and development in the $21^{\text {st }}$ century. The Climate Conference in Copenhagen in 2009, for instance, included government-level debate on how to achieve responsible and sustainable urban growth whilst preventing global warming and climate change. Sustainability means more than the protection of the environment; it also requires a long-term vision for catalyzing positive change leading to sustainable social and cultural contexts in relation to the built environment (Newman and Jennings [1]). This vision needs to reflect the distinctive nature and characteristics and identities of each city.

The vision should also express the integrated values and identity of the people for their cities to become more sustainable. Newman and Jennings [1] noted that a vision based on sustainability will help align and motivate communities, 
governments, businesses, and others around a common purpose, and will provide a basis for developing a strategy, an action program, and processes to achieve that vision.

Considering this collective determination for achieving sustainability in urban visions, this paper provides a systematic framework for discussing a new model, which can suggest new possibilities to both designers and decision makers, particularly using the case of the Multifunctional Administrative City (MAC) project in South Korea, and also guide sustainable design alternatives in relation to urban design criteria and practices. This framework is set out so that it is responsive to how place and function can be adapted to achieve sustainability in different cases and contexts.

\subsection{Interpretation of sustainable development}

The notion of sustainability can be defined not as some fixed perfect state, but rather an evolving one that responds to both change in the form production processes as well as ecological change. The UK Government's reformulation of the Brundhand definition of sustainable development using the term 'a better quality of life' was published in its sustainable development strategy of 1999 (Wilson [2]). Brandon and Lombardi [3] also noted that sustainable development is a process of change in which exploitation of resources, the orientation of technological developments and institutional change are all in harmony.

This process is about creating a learning environment in which all participants strive to improve the situation that exists for the needs of today and tomorrow, acknowledging aspirations as well as needs and therefore engaging the drive for change and improvement within society. These arguments underline that a change of approach is needed, in which the wider sustainable objectives are part of the agenda for change.

This paper intends to provide a spatial assessment tool in terms of environmental sustainable management, to help measure the contribution of sustainable development beyond the perceptions changes, needs change, the technological infrastructure changes, and developments in scientific knowledge.

\subsection{The impact of the built environment}

Over the last 25 years, the UNFCCC and other international societies (FSD, IISD, ISDRS, ISBE) have proposed that governments worldwide should address the rising levels of air pollution and greenhouse gases produced within cities. Given the finite natural energy resources involved, these recommendations and proposals include special consideration for alternative approaches to the generation of energy within urban development.

The impact of climate changes brought about through rapid urban development and infrastructural growth in developing countries, including within the South East and East Asian region, has meant that these developing countries have started to respond to the need for alternative approaches to this development and growth. For example, recent statistics regarding South Korea 
(ABB [4]) show that consumption associated with the built environment is as follows:

- Total consumption of each person in the South Korea averages 12.4 tonnes of material per year, of which 3.9 tonnes stems from new industries, buildings, and new infrastructure

- Up to $70 \%$ of total energy use can be directly or indirectly attributed to buildings and infrastructure.

To provide an international comparison from other continents, research by McGrawHill Construction (Bernstein [5]) shows that Sub-saharan Africa devote $58 \%$ of total energy to the construction of commercial and residential buildings, Australia / New Zealand devoting 20\%, and Asia sitting between these extremes at $41 \%$. These statistics highlight how important the built environment is to any policy and evaluation of environmental sustainability.

Considering this, how can the built environment respond to the need for sustainability? Whilst involving a complex range of issues, one key aspect is understanding the relationship between each element of the built environment and sustainable development policy. The built environment is largely determined by the communities that dwell there and the buildings reflect the needs of the individuals and different key actors, physical and social structure, and the physical location of the structures (Carmona [6], Lee [7], Bentley [8]).

However, when identifying a response to the issues of sustainability within the built environment it is sometimes difficult to define the key milestones to be considered in relation to physical, social, economic and scientific contexts. As such, the establishment of a framework in relation to the values of environmental management values can provide a logical and coherent approach to the consideration of these diverse contributions and other criteria.

\subsection{Extension of the issues: using the case study}

A main case study of the MAC (Multifunctional Administrative City) construction project in South Korea is undertaken in this paper to provide the conceptual and empirical model for the creation of a more sustainable form of urban development, with the findings and conclusions underpinned by the concept of value. The purpose of the selected case study is to measure the dimensions of sustainable development and the difference between different key actors' aspirations and needs for sustaining their life in the built environment.

\subsection{Methods}

In order to map the urban design process in the new place making of the MAC project, data was collected using a variety of methods. The most commonly used method was a series of semi-structured interviews that allowed feedback to be gained from different key actors regarding their knowledge, experience, and sense of identity and sustainability in new place making. These interviews were conducted with government, local authorities, public and private producers, developers, non-governmental organizations, and residents. Other methods of obtaining information involved direct observations within the field, 
questionnaires and the gathering of archival material such as government documents, newspapers, reports, previous research work and policy documents.

\section{The response to the built environment: reviewing the MAC project in South Korea}

In 2003 the nation of South Korea announced plans to create a new sustainable and green city, the Multifunctional Administrative City (MAC). The fundamental goals of this new city were described as social redistribution, population redistribution and spatial reorganization, whilst attracting global investment to support industrial growth at the local level and the forming of a finance and economic hub in South East and East Asia at the international level (Park and Lee [9]).

The development of the MAC was initiated in response to what the Korean government saw as problems with overpopulation, over-development, and environmental problems such as air pollution, micro-climatic changes and an over-stretched infrastructure debilitating the metropolitan city of Seoul. As the name suggests, the intention was that the new city be multifunctional. Together with the creation of a new political and administrative space, the new city was designed with a relatively large proportion of public green space, with zones for growth industries and a sustainable transportation infrastructure. The aspiration was for an advanced hi-tech and sustainable city that would be globally competitive.

The MAC will be located $150 \mathrm{~km}$ south of Seoul, in the Chungcheongnam-do region (see Figure 1). The construction of the Multi-functional Administrative City is a large-scale project with a planned 20 year construction period, due for completion in 2030. Currently in 2011, the first residential district has been constructed and the first inhabitants are starting to arrive (MACC [10]).

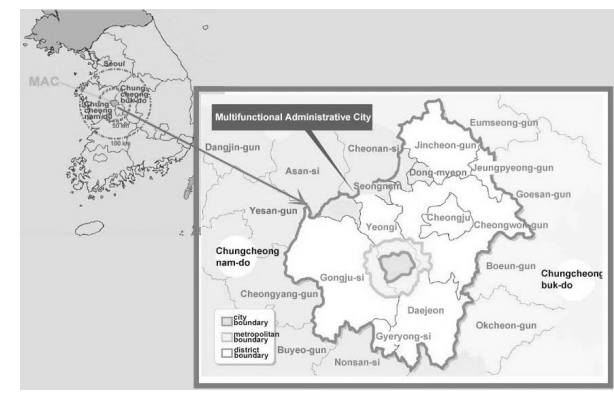

Figure 1: Location of the MAC within a national and regional context (source MACC, 2006).

Following the overall design concepts of the MAC masterplan, the ring shaped city structure (see Figure 2) was chosen and developed as a sustainable transportation system. The initial concept of the overall masterplan proposed the creation of a city with social organization, facilities, activities and dwellings 
bonded together by the interstitial general facilities (MACC [10]), as a new environmentally and socially sustainable future-oriented city, rooted in the cultural and local context, together with a removal of the traditional centralization of density within urban activities.
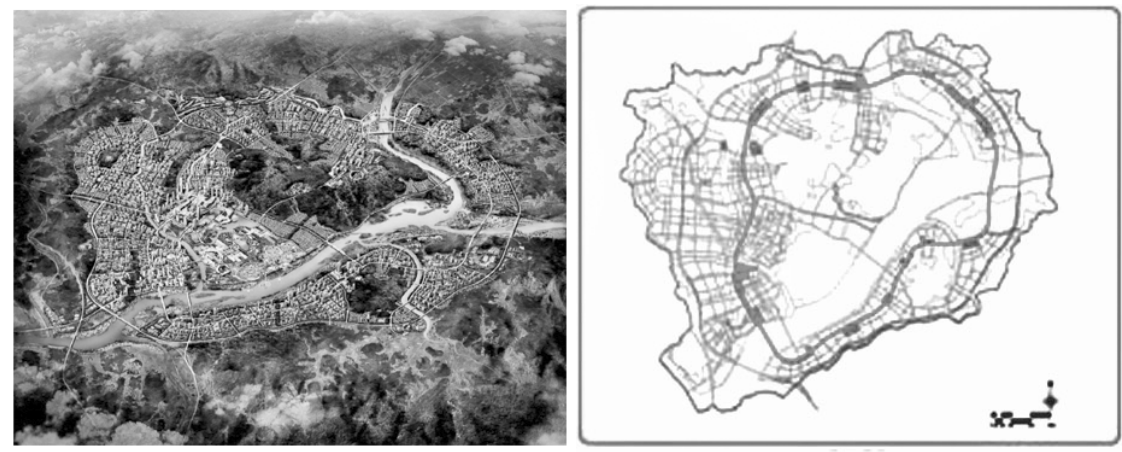

Figure 2: Overall design concept for MAC masterplan and ring shaped infrastructural and public transportation linkage of the city (source: Happycity2030, 2009).

In detail, the design proposal combines rural landscape and urban built form into a series of self-sufficient urban districts, stitched together with a ring shaped transportation, services and digital infrastructure. Three different levels of urban morphological development were further proposed - Natural-sphere, Citysphere, and Net-sphere, where the city meets the valley and the surrounding landscape, are places where the three spheres- rural, urban, and digital- overlap. According to the overall design concept, the ring-shaped spatial structure reflects a sustainable approach in its ambitions for a harmonious, 'democratic' city, a removal of hierarchy, and environmentally sustainable city by transportationoriented development.

Whilst the MAC infrastructure and transport proposals include certain components that consider the environment, such as electric buses and electric car charging points and incentive to ownership, there are many other environmental solutions adopted by other cities that the MAC haven't as yet considered within their proposals. These include congestion charge / additional charges levied on single passenger car users, car-share schemes and low-cost bicycle hire network.

Understanding the concepts of the MAC masterplan, it is useful to consider Krier's argument [11] that the masterplan is to the construction of a city what the constitution is to the life of a nation. Establishing a masterplan is much more than a specialized technical instrument and is the expression of an ethical and artistic vision. The masterplan thus shows the legislative form of such a vision, the geometric expression together with the necessary socio-cultural and political strategies for sustainable implementation.

Whilst considering sustainability it is important to recognize that physical built form is continuously evolving to suit changes to global aspirations and local needs, together with the impact of dynamic social and economic influences 
(Whitehand [12]). In parallel, Lynch [13] argued that places and cities are deeply related to the social, economic, and political pressures influencing the decision makers' power and control in urban development and urban settings. In the following section the details of sustainable development in morphological levels and design concepts are considered in order to identify what do the decision makers for the MAC project value when creating a sustainable city.

\subsection{Ecological sustainable development}

\section{Sustainable Geography and Landscape}

The MAC site has a picturesque setting, surrounded by a mountain range including four peaks- Guksa Peak (214m), Goehwa Mountain (200m), Wonsu Mountain (254m), and Jeonwol Mountain (260m), with the Gum river running through the central valley (MACC [10]). The present usage of this site is predominantly agricultural, with a small local community that originated in the 15 th Century.

Whilst retaining the four main peaks noted above, the further development led by key decision makers within the governmental MAC planning agency currently includes an erasure and levelling of much of the remaining natural topography. In the UK, concurrent with this development of the MAC, there is a growth in urban development based on the principle of protecting and maintaining original landscapes and topography when developing land, including historic environments and cultural landscapes (PPG 15 [14]). In contrast, and although the policy and design strategies promote the MAC as an ecologically sustainable city, $49 \%$ of the landscaped areas and waterways within the MAC masterplan are newly formed. From an ecological perspective and when looking at whether a city can be rooted and sustained by utilizing local resources, this new design proposal and development poses the crucial question: what are the authentic local values that should be sustained and evolved for this futureoriented city?

Prior to the commencement of the MAC construction, the original positioning and arrangement of the traditional towns and agriculture within the area were based on the concepts of geomancy, or fengshui. Fengshui is not about looking at nature as an object to be analyzed but is about looking at nature as an equal (Kilburn [15]). It sees every object having a life of its own, and the energy circulates through everything. This morphological landscape and landuse of the MAC relates to the northern and southern sides of the city each having a particular morphological character, surrounded by mountains and water, and the harmony of the overall direction of the town considered in relation to the sun's path and the prevailing direction of the wind. The careful consideration of the theory of Fengshui that has been a constant of the traditional agricultural landuse of the area, could be extended as a sustainable approach when considering evolving types of sustainable thinking in relation to Korean urban development.

Coupled with the influence the traditions of Fengshui could have on orientation in relation to the topography, climate change has also brought with it some urgent practical considerations, such as rising water levels and the potential for flooding. These factors should also now influence the location of 
developments, and the design or planning of such things as flood defense mechanisms, within the first stages of development.

The MAC design proposals include innovative design approaches to the city's form and function with energy saving modern housing types (see Figure 3). The aim of the MAC proposals are to construct this new city in a way that strives towards some self-sufficiency and efficiency in energy provision and production through diverse functions and a broad range of housing types and commercial activities, set within an ecological environment. The overall design concept of the MAC for energy provision includes renewable sources such as geo-thermal energy, bio-mass and fuel-cell heating and solar power. As a test case for new energy saving housing typologies in MAC are particularly influenced by the European passive housing approach to energy efficient building.
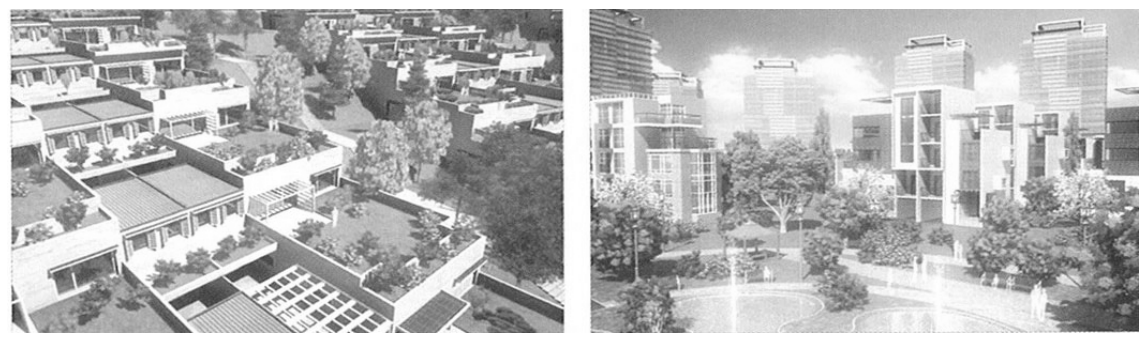

Figure 3: MAC energy saving modern housing typologies (source: MACC, 2008).

However, where the MAC proposals for environmental building techniques are currently lacking is that they are not considering ways to reduce the carbon footprint of the building process by using local resources and locally sourced construction materials. The traditional Hanok (see Figure 4) housing provides a good reference for how the use of local materials and traditional building techniques can be done in such a way that is both environmentally and culturally sustaining.

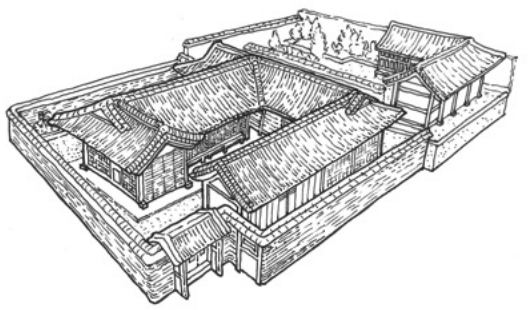

Figure 4: $\quad$ Traditional Hanok housing typology (source: Author, 2011).

In summary, within the concepts of the hard-tissue design for the new city, the MAC may be viewed as a construct of unique geographic, physical and environmental characteristics, combined with unique cultural circumstances and 
subsequent human interventions over time. However, communities' experience through social activities and cultural engagement generate distinctive experimental characteristics, and the sustainable locality is established when these characteristics complement the physical elements of built form for the present and future generations. Butina Watson and Bentley [16] described this as 'the multi-sensory process of inhabiting a place's structure and open spaces those landscapes modified by human intervention which geographers call "cultural landscapes". The sustenance of the cultural landscape within the MAC region will require the embedding of approaches to both physical and social sustainability within the built form process.

\subsection{Seeking a shared value: social and cultural sustainability}

When compared to the concept of physical sustainable development, Bentley (2009) argued that if the development of the character of the new city will involve some integration of the local historical and social context, it is important that the local context and resources be positioned within a pre-conceived strategy that refers not just to the past, but also to an open sense of the future. Considering Bentley's argument, the local area around the MAC site reveals a historical identity based around the growth and ancestry of two families, the Lim family, dating back 600 years, and the Lee family, dating back 350 years. The rootedness of these two families and the strong agricultural community that has organically grown up around them is an important and unique local resource that could inform the sustainable characteristics of the MAC. Rather than retain and integrate the existing local community's culture, the MAC development proposals include for these communities be deconstructed and cleared to make way for a new group of people and a new approach to place-making. Lynch [17] argued that although an environment, such as agricultural land, can be associated by some to epitomise an old-fashioned, out-dated way of life, these environments can have a strong character worth sustaining. His argument suggests that it is worth considering the peculiar characteristics of these agricultural areas and the local community's usage and engagement as a social value and resource to be sustained. This traditional way of life may not be totally consistent with the outlined objectives for this new town, or be the most economically efficient use of the land from the producers' perspective, but this traditional usage could provide an important sustainable dimension to the evolved local identity of the new town.

In the development of many cities and towns, the possibility of a clear and unitary urban image is overwhelmed by the perceived logic of the developer, which compromises not only the operability of plans and regulations conceived so far, but also the legibility of unitary forms, boundaries, and historical traces. Within the MAC project, the vision of the decision makers to create a unitary image of the city is also the dominant force driving the global aspirations they have to create a 'production' of a green city. However, as argued by Lynch [17] above, the MAC design proposals could be more sensitive towards how the existing site and the community's experience and activity has developed over centuries, together with the built form that has already been 'produced'. 
Having discussed the MAC design proposal in relation to the value of local resources and historical characteristics of the region, the following counter proposal and landscape development illustrate cultural engagement and sustainability at a local level. For instance, the counter proposal masterplan concept for the first residential district of the MAC project is by Korean architect Young-Joon Kim. He proposes the establishment of a cultural and historical network to link the existing vernacular buildings and local community. The intention is that the original historical buildings can create a network of places and life within the local community, as a way of evolving a rooted and sustainable urban form and function.

Although the notion of a compact city with high density has been developed as a sustainable solution for sustainable city by many researchers and across many countries (Jenks and Jones [18], Lepeska [19], Kenworth [20]), Yu and Hein [21] argued that highly compact, high density cities can reach a point beyond which negative aspects such as pollution and congestion, and as such this compact approach may be an inappropriate solution for the creation of an environmental eco-city. When considering these arguments in relation to the MAC development, Kim noted that the replacement of the great 'narrative' of the MAC decision makers with a network of many small stories, low density, stitched together with public transportation and green space. This alternative city pattern would assume the form of a community network of self-sufficient neighbourhoods. In addition, his proposed alternative approach to the MAC exposes a lack of flexibility and diversity in the current design approach that the local community and culture can engage with in order to develop a sustainable new city that can cross over physical and social boundaries.

One example of a progressive and responsive approach to the development of the MAC site concerns the protection of the landscape heritage of the area. A local community group and university staff have been working together to transplant some local indigenous plant species from the site prior to construction (Choi [22]). These are being cultivated in the Botanic garden in Seoul and the intention is to transplant them back to the MAC once construction work has been completed.

In light of that, the analysis of the design concept and strategies for the MAC show that the importance of these local resources and social and cultural contexts haven't been comprehensively integrated within the physical built environment in relation to sustainable development. The MAC development Agency could develop sustainable policies by working more closely with the community groups that are trying to save the local landscape species.

\section{The consolidated findings for spatial assessment of sustainable urban development strategies}

Modern urban development often produces monotonous and uniform products of the built environment that simply follow global trends and design ideologies led by the power and ambition of the decision makers in place. The MAC project, particularly with regards to methods of sustainable development, has the 
opportunity to be different. The analysis within this paper aims to provide a better understanding of the needs of social and physical integration in the design process that will determine whether this opportunity can be taken, and the influence the different key actors' can have in the generation of the future oriented and sustainable MAC project.

In order to provide a sustainable city rooted in specific social and cultural contexts, this paper provides an evaluation of whether there are limitations to the creation of place-identity within the MAC and if so why this is the case, and how the place-identity of a newly designed built environment can marry with the concepts of sustainable urban development, in both practice and policy.

Based on an understanding of the values of the decision makers for the case of the MAC, six hard tissue approaches to the achievement of a sustainable built environment can be articulated as spatial assessment elements: 1) Location; 2) Sustainable land use; 3) Sustainable infrastructure (recycled water management system); 4) Sustainable green public transportation system, but the consideration of electric car charging points and incentive to ownership, congestion charge / additional charges levied on single passenger car users, car-share schemes; 5) Energy saving buildings (Sola system, passive solar housing types, lighting, air circulation, LED, etc.), but using local resources and locally sourced construction materials; 6) New approaches to recyclable energy systems (sunlight, geothermic, fuel cell, bio-mass, etc.).

In addition, two findings in relation to the soft tissues within the built environment need to be given value as part of a response to spatial assessment strategies within sustainable development: 7) The sustenance and evolution of local resources and values rooted in culture and history; 8) An integrated understanding of both the producers' and the users' perceptions of the cultural and social contexts.

In summary, this collaboration of elements provide a spatial assessment framework for discussing a new model, with suggestions for sustainable design alternatives in relation to the impact of urban design principles and practices, focusing not only on the development of the MAC, but also towards sustainable urban development in other cities in South Korea.

\section{Conclusion}

This paper discussed how we can assess and value sustainable forms of development, whilst considering social and cultural contexts, in the creation of environmentally sensitive cities, using as a particular case the MAC in South Korea. Within the contemporary urban development context, many cities have recognized the importance of sustainability in delivering better qualities of cities and spaces in which to live, across different continents, climates, and cultures. This recognition is resulting in the development of a particular type of distinctive, habitable built environment rooted in the past yet future-orientated.

Having discussed the creation of a sustainable urban city, traditional cultural empowerment and eco-city social movements are providing a revitalized sense of place and demonstrating new ways of living, shifting from rapid development 
and mass consumption to urban eco-villages. This movement shows how local communities can be engaged and empowered in urban development to develop and sustain their quality of life. Citizens' participation and decision makers' supportive, effective governance are important elements within this.

In order to achieve these ambitions, decision makers, planners, and designers could consider and acknowledge the integration between their needs and the aspirations of the design ideology. The social, political and cultural influences, together with local resources and technology, could be utilized to construct proposals for how a particular design model can be generated within the creation of a sustainable future-oriented built environment. Given the wide variety of social and cultural contexts, it is difficult to reach a general conclusion and recommendations for design concepts. However, through using the particular case study of the MAC this paper can offer some guidance towards design practice in the creation of sustainable place-making, whilst providing a basis for developing a strategy and process to achieve a sustainable urban vision in order to deliver better quality of life across different continents and cultures. Also it can contribute to defining the importance of a greater consideration for cultural engagement and empowerment in sustainable development, via a shift in political and social ideology within the urban environment.

In conclusion, the creation of a sustainable city does not only concern the creation of a more secure, more beautiful, more efficient and cost-effective city, but requires a consideration of the sustainability of urban life and the development of a built environment that shares a common purpose among different users, designers, decision makers and the natural environment.

\section{References}

[1] Newman, P., and Jennings, I., Cities as Sustainable Ecosystems: Principles and Practices, Island Press: Washington, D.C., 2008.

[2] Wilson E., Local Environmental sustainability: Skeletal Frameworks (eds.) Buckingham. S., \& Theobald. K., CRC Press: Boca Raton Boston New York Washington, D.C., pp18-45, 2003.

[3] Brandon, P., and Lombardi, P., Evaluating Sustainable Development in Built Environment, 2nd Edition, Wiley-Blackwell: London, 2011.

[4] ABB: Country Report: South Korea: Trends in global energy efficiency. Online. http://www.abb.com

[5] Bernstein, H., Global Green Building Market Trends: Results from the First.International Study. Online. http://www.construction.com

[6] Carmona, M., Public Places-Urban Spaces: the Dimension of Urban Design, Architectural Press: Oxford, UK, 2003.

[7] Lee, H. S., The Concept of Le Corbusier's architecture and urban planning, TaeLim Press: Seoul, South Korea, 2002.

[8] Bentley, I., Urban Transformation: power, people and urban design, Routledge: London, 1999.

[9] Park, D., Lee, J., (eds.), Global Innovation Clusters, Hanul Academy, 2004. 
[10] Multifunctional Administrative City Design Policy and Concepts, http://happycity2030.or.kr

[11] Krier, R., Architecture \& Urban Design: 1967-1992, Academy Editions: London, 1992.

[12] Whitehand, J.W.R. (eds). The Urban Landscape: Historical Development and Management: Papers by M. R. G. Conzen, Institute of British Geographers, Special Publications, Academic Press: London, UK, 13. 1981.

[13] Lynch, K., A theory of good city form, Massachusetts Institute of Technology: Cambridge, 1981.

[14] Planning Policy Guidance15: Planning and the Historic Environment, Online, http://www.communities.gov.uk/documents

[15] Kilburn, D., Feng shui, Online, http://www.kahoidong.com

[16] Butina Watson, G., Bentley, I., Identity by Design, Architectural Press: Oxford, UK, 2007.

[17] Lynch, P., The Image of the Contemporary City, International Conference for $16^{T H}$ International Seminar on Urban Form, $4^{\text {th }}-7^{\text {th }}$ September, South China University of Technology and Guangzhou Urban Planning Bureau, Guangzhou, Guangdong, China, 2009.

[18] Jenks, M., and Jones, C., Dimensions of the Sustainable City, Springer: London, UK, 2010.

[19] Lepeska. D., Sustainable Cities are the Solution, Online, http://www.guardian.co.uk

[20] Kenworth, J. R., The Eco-City: Ten Key Transport and Planning dimensions for sustainable City Development, Environment and Urbanization, 18 (1), pp 67-85, 2006.

[21] Yu, C., and Hien, W.N., Thermal Impact of Strategic Landscaping in Cities: A review, Advances in Building Energy Research 3(1), pp237-260, 2009.

[22] Choi, H.S., Place Identity in $21^{\text {st }}$ Century contemporary new town development in South Korea, unpublished $\mathrm{PhD}$ Thesis, Oxford Brookes University, UK. 2011. 